\title{
Impaired prepulse inhibition of acoustic and tactile startle response in patients with Huntington's disease
}

\author{
Neal R Swerdlow, Jane Paulsen, David L Braff, Nelson Butters, Mark A Geyer, \\ Michael R Swenson
}

\begin{abstract}
The corpus striatum serves a critical function in inhibiting involuntary, intrusive movements. Striatal degeneration in Huntington's disease results in a loss of motor inhibition, manifested by abnormal involuntary choreiform movements. Sensorimotor inhibition, or "gating", can be measured in humans using the startle reflex: the startle reflex is normally inhibited when the startling stimulus is preceded $\mathbf{3 0 - 5 0 0 ~ m s ~ e a r l i e r ~ b y ~}$ a weak prepulse. In the present study, prepulse inhibition (PPI) was measured in patients with Huntington's disease to quantify and characterise sensorimotor gating. Compared with age matched controls, patients with Huntington's disease exhibit less PPI. Startle gating deficits are evident in patients with Huntington's disease when startle is elicited by either acoustic or tactile stimuli. Even with stimuli that elicit maximal PPI in normal subjects, patients with Huntington's disease exhibit little or no PPI, and their pattern of startle gating does not show the normal modulatory effects usually elicited by changing the prepulse interval or intensity. Startle amplitude and habituation and latency facilitation are largely intact in these patients, although reflex latency is significantly slowed. In patients with Huntington's disease, startle reflex slowing correlates with cognitive impairment measured by the dementia rating scale, and with the performance disruptive effects of interference measured by the Stroop test. These findings document a profound disruption of sensorimotor gating in patients with Huntington's disease and are consistent with preclinical findings that identify the striatum and striatopallidal GABAergic efferent circuitry as critical substrates for sensorimotor gating of the startle reflex.
\end{abstract}

(F Neurol Neurosurg Psychiatry 1995;58:192-200)

Keywords: Huntington's disease; startle response; prepulse inhibition

The corpus striatum is thought to facilitate the maintenance of posture and ongoing motor behaviours, and to inhibit or gate inappropriate, involuntary movements. ${ }^{1}$ These critical functions are accomplished via striatal $\gamma$-aminobutyric acid (GABA) containing efferent projections to portions of the globus pallidus and zona reticulata of the substantia nigra, which in turn modulate thalamic motor nuclei directly or indirectly vir. the subthalamic nucleus. ${ }^{2}$ Patients wirh Huntington's disease experience a progressive degeneration of intrinsic striatal cells, particularly the medium spiny, or spiny I, GABAergic efferent neurons. ${ }^{3}{ }^{4}$ As a result, striatal gating mechanisms fail and adventitious choreiform movements develop in Huntington's disease, progressing to athetosis.

Impaired gating of motor responses can be quantified from the startle reflex. This reflex is normally inhibited when the stimulus-typically a loud noise or air puff-is preceded about $100 \mathrm{~ms}$ earlier by a weak prepulse. ${ }^{5}$ Prepulse inhibition (PPI) is an operational measure of sensorimotor gating: the degree to which the involuntary startle response is inhibited by a weak prepulse reflects the amount of sensorimotor gating. The PPI seems to largely reflect hardwired inhibitory gating processes: it is involuntary and not learned, occurring on the first stimulus presentation and persisting thereafter without habituation. ${ }^{5}$ Startle reflex and PPI can be quantified in humans from the eyeblink component of the reflex with surface EMG recordings from orbicularis oculi. Preclinical measures of startle and PPI in laboratory animals can be accomplished with EMG or accelerometer based measures of individual muscle groups or whole body movement.

As described by Davis and colleagues, ${ }^{6}$ the acoustic startle reflex is controlled by serial connections between the auditory nerve, cochlea, lateral lemniscus, nucleus reticularis pontis caudalis, and the spinal motoneuron. Whereas the primary startle response is controlled within the pontine reticular formation, startle reflex plasticity-including PPI-is modulated by forebrain circuitry. In rats, PPI seems to be modulated by neural circuitry connecting the hippocampus, ${ }^{78}$ ventral striatum, ${ }^{9-12}$ subpallidum, ${ }^{7}$ and pedunculopontine tegmental nucleus, ${ }^{13}$ which may access the primary startle circuit via pontine tegmental efferents to the nucleus reticularis pontis caudalis. ${ }^{6}$ Manipulations at several levels of this forebrain gating circuitry in rats can modify the normal inhibitory effects of a prepulse on the startle reflex. ${ }^{11} 12$

Based on these preclinical findings, it is possible that striatal degeneration in Huntington's disease would be accompanied by dysfunction within startle gating circuitry 
and a consequent loss of PPI. In this study, we investigated the loss of gating mechanisms using the startle reflex in patients with Huntington's disease. If PPI is diminished in such patients, this objective, quantitative evidence of impaired gating might have clinical utility in evaluating those at risk, response to treatment, or the progression of the illness and its underlying neuropathology, and might even be a valuable phenotypic marker for genetic linkage studies.

\section{Methods}

Twenty two patients (15 men, seven women, mean age 50.05 (SEM) 2.94 years) were recruited over a three year period from the UCSD Genetically Handicapped Person's Program. Diagnoses of Huntington's disease in all patients was based on a combination of typical clinical symptoms and signs, neuropsychological deficits, positive family history, reduced caudate volume from MRI (when available), and exclusion of other diagnoses by neurological examinations, laboratory tests, and neuropsychological batteries. Dementia rating scale $^{14}$ scores collected within one year of startle testing for most patients showed that cognitive impairment ranged from mild to severe (mean dementia rating scale score $=118.05$ (SEM 3.88); range 68-141). Exclusion criteria comprised other serious medical or psychiatric illness, substance abuse in the past year, and history of open head trauma or sustained unconsciousness or schizophrenia in a first degree relative. Histories were verified with family members. Most patients were treated with some form of dopamine antagonist; in preclinical ${ }^{15}$ and clinical studies, ${ }^{16}$ these agents tend to increase PPI, and thus any deficits in PPI in patients with Huntington's disease would not likely be attributed to these medications.

Twenty two control subjects (15 men, seven women, mean age 40.05 (SEM) 2.82 years) were recruited from the community; an effort was made to match controls and patients with Huntington's disease by age and sex. As well as the exclusion criteria described, control subjects were screened for psychopathology with an established algorithm based on the Minnesota multiphasic personality inventory (exclusion at Goldberg indices $\geqslant 60$, Wiggins psychotocism $\geqslant 60$, or F scale $\geqslant 70$ ). ${ }^{17}$ Others (session 2 ) received a urine toxicology screen, and were excluded on the basis of any positive drug findings. Among the final control sample, no subjects had abnormal Minnesota multiphasic personality inventory results or abnormal toxicological findings.

The acoustic startle response was measured between 0900 and 1700 with two different EMG systems (San Diego Instruments, San Diego, CA, USA). Hearing was screened with a Saico audiometer (Saico SCR-2, Assens, Denmark). Subjects were excluded if they showed impairment at $40 \mathrm{~dB}(\mathrm{~A})(1000 \mathrm{~Hz})$. The eyeblink component of the startle reflex was assessed from EMG measurements of orbicularis oculi, as described elsewhere. ${ }^{18}$ Briefly, each subject was seated comfortably adjacent to the recording equipment and in view of a trained technician. Two miniature silver/silver chloride electrodes (Sensor Medics, Anaheim, CA, USA) were positioned below and to the right of the subject's right eye, over the orbicularis oculi muscle. Placement was selected such that when subjects were asked to move their eye position virtually no activity was recorded with oscilloscope monitoring. ${ }^{18}$ Electrode resistances were $<5 \mathrm{kohm}$. Recorded EMG activity was bandpass filtered $(1-1000 \mathrm{~Hz})$, and a $60 \mathrm{~Hz}$ notch filter was used to eliminate $60 \mathrm{~Hz}$ interference. A ground electrode was placed behind the right ear over the mastoid; EMG activity was digitised and 250 readings of $1 \mathrm{~ms}$ were recorded starting at startle stimulus onset. Acoustic startle stimuli were delivered by Telephonics (TDH-39-P, Maico, Minneapolis, MN, USA) headphones, and tactile air puff startle stimuli were delivered from a compressed air tank to the subject's neck via a small rubber tube. Subjects sat upright and were directed to look straight ahead and to stay awake.

Subjects were tested in two separate paradigms. One paradigm (session $1 ; 11$ controls and 11 patients with Huntington's disease) assessed startle amplitude and PPI with two pulse modalities (acoustic and tactile) and three different intervals between prepulse and pulse $(30,60$, and $120 \mathrm{~ms})$. In the initial part of this session, a background $70 \mathrm{~dB}(\mathrm{~A})$ white noise was followed five minutes later by 73 trials in which a startle response was elicited by a $116 \mathrm{~dB}(\mathrm{~A}) 40 \mathrm{~ms}$ noise burst. An initial pulse (P-ALONE) trial was followed by 72 trials consisting of six blocks of 12 trials each. Each of these 12-trial blocks included three $P$-ALONE trials, and nine trials in which pulse was preceded 30,60 , or 120 ms earlier by a prepulse ( $20 \mathrm{~ms}$ burst) that was $15 \mathrm{~dB}(\mathrm{~A})$ above background (" $30 \mathrm{~ms}$ ", "60 ms", or " $120 \mathrm{~ms}$ " respectively). In the later part of this session, 31 tactile trials were given. An initial PUFF trial consisted of a 30 pounds/square inch air puff delivered through a rubber tube placed about $5 \mathrm{~cm}$ from the subject's suprasternal notch. Tube diameter was $4 \mathrm{~mm}$ with air pressure delivery regulated at the air supply. The initial PUFF trial was followed by five blocks of six trials that were either PUFF or PUFF preceded $120 \mathrm{~ms}$ by an acoustic prepulse as described earlier (prepulse + PUFF). For acoustic and tactile trials, a variable between trial interval averaged 15 seconds. Session 1 used one stationary EMG system located in a research laboratory (DLB) and covered a period of about 1.5 years.

A second paradigm (session $2 ; 11$ controls and 11 patients with Huntington's disease, none of whom were tested in session 1) assessed startle amplitude and PPI using acoustic stimuli only, a single prepulse interval $(60 \mathrm{~ms})$, and four different prepulse intensities $(2,4,8$, and $16 \mathrm{~dB}(\mathrm{~A})$ above background). A background $70 \mathrm{~dB}(\mathrm{~A})$ white 
noise was followed five minutes later by 72 startle trials consisting of three conditions: (1) a $118 \mathrm{~dB}(\mathrm{~A}) 40 \mathrm{~ms}$ noise burst presented alone (P-ALONE); (2) the same $118 \mathrm{~dB}(\mathrm{~A})$ $40 \mathrm{~ms}$ noise burst preceded $60 \mathrm{~ms}$ by prepulses (20 ms noise bursts) that were $2,4,8$, or $16 \mathrm{~dB}(\mathrm{~A})$ above background (PP2, PP4, PP8, or PP16); or (3) no stimulus. These six trial types were repeated six times in pseudorandom order; this block of 36 trials was repeated twice for a total of 72 trials. A variable between trial interval averaged 30 seconds. Session 2 used a portable EMG system in the UCSD Huntington's disease clinic, over roughly a 1.5 year period. Startle sessions are not painful, and are approved by our Human Subjects Institutional Review Board.

To assess the level of "cognitive" inhibitory deficits in these patients with Huntington's disease, the Stroop test ${ }^{19}$ was given to most subjects tested in session 2 . Briefly, subjects read for 45 seconds from a standardised list of the words, "blue", "green", or "red", presented in random order, and the number of words correctly read in that 45 second period was recorded (word task score). Next, for 45 seconds subjects named the colour of patterns within a standardised list of blue, green, or red coloured patterns presented in random order, and the number of colours correctly identified in that period was recorded (colour task score). Finally, subjects identified the colour of ink that was mismatched to a word (for example, the word "red" printed in blue ink should be identified as "blue"), and the number of correct responses in a 45 second period was recorded (interference task score). The Stroop test has been used as a measure of cognitive inhibition, because the interference task requires the subject to inhibit or gate the response to the semantic value of the word and to attend to its colour content. ${ }^{19}$ Our previous studies have found no significant correlation between PPI and Stroop interference scores in a normal population. ${ }^{20}$

Dependent measures for the startle reflex included startle amplitude, peak startle latency, reflex habituation, and PPI. All amplitude measurements were based on the first component $\left(R_{1}\right)$ of the startle response. For tactile trials, latencies were corrected for the $18 \mathrm{~ms}$ delay between computer generated stimulus onset and delivery of the air puff stimulus. The PPI was defined as the \% reduction in startle amplitude in the presence of the prepulse compared with the amplitude in the absence of the prepulse $(100-(100 \times$ amplitude on prepulse trial/amplitude on P-ALONE trial)). Thus a large "\% score" indicates more PPI, whereas a smaller "\% score" indicates less PPI. Statistical analyses consisted of mixed design analyses of variance (ANOVAs) with appropriate post hoc tests. Amplitude of P-ALONE and PPI were analysed by two way ANOVAs with repeated measures on trial type (within subject) and diagnosis (between subject). The $a$ value was $0 \cdot 05$.

As in other studies of human startle response, ${ }^{182326}$ some subjects in each group were characterised by a relative lack of startle stimulus elicited eyeblink EMG activity and were therefore eliminated from the subsequent analyses of startle data. Subjects were identified as "non-responders" based on knowledge of their P-ALONE values only and cut off values were determined by inspection of the overall sample distribution. Specifically, we examined a histogram of mean startle amplitudes from a large population of control subjects tested in each session. Values tended to form a normal distribution, with the exception of a small cluster of very low values. For each session, criteria for "non-responders" were selected to exclude from analysis subjects with these very low values, leaving for analysis most subjects, whose values were normally distributed. These same criteria were then applied to the patients with Huntington's disease. Consistent with previous studies completed with this apparatus, ${ }^{18}$ in session 1 , a non-responder was defined by an average acoustic startle P-ALONE amplitude $<25$ units or an average PUFF amplitude $<10$ units $(1$ unit $=$ approximately $7 \cdot 7 \mu \mathrm{V}$ ). With these criteria, non-responder rates in patients with Huntington's disease were comparable with those in controls tested with this apparatus for both acoustic startle (control rate = $32 \%$, Huntington's disease rate $=30 \cdot 8 \%$ ), and tactile startle reflexes (control rate $=$ $12 \%$, Huntington's disease rate $=16 \cdot 6 \%$ ). Session 2 was divided into two trial blocks. Data were analysed only for trial blocks where P-ALONE amplitude exceeded 10 units. With these criteria, two trial blocks were excluded from patients with Huntington's disease $(9 \cdot 1 \%)$, comparable with exclusion rates in controls tested with this apparatus $(9.0 \%)$.

\section{Results}

Figures 1-4 present the results. In session 1, startle amplitude on P-ALONE trials did not differ between controls or patients with Huntington's disease (mean amplitudes (SEM): control = 56.73 (8.35); Huntington's disease $=49.11 \quad(9.92) ; \quad F<1)$. Similarly, startle amplitude on PUFF trials did not differ between controls or patients with Huntington's disease (mean amplitudes (SEM): control $=66.33(17 \cdot 12)$; Huntington's disease $=98.89(28.85) ; F<1)$. Thus patients with Huntington's disease exhibited normal startle amplitude in both acoustic and tactile modalities.

Prepulse inhibition was impaired in patients with Huntington's disease compared with controls in both acoustic and tactile modalities (fig 1A). An ANOVA with repeated measures on trial type for acoustic trials showed an effect of diagnosis $(F=7 \cdot 76$, df $1,16, p<0.015$ ), no effect of trial type $(F<1)$, and no diagnosis $\times$ trial type interaction $(F<1)$. Control subjects had the normal modulatory pattern of PPI, with more inhibition elicited by $120 \mathrm{~ms}$ intervals than by 30 $\mathrm{ms}$ intervals, ${ }^{51}$ whereas patients with Huntington's disease failed to show this modulatory effect of increasing prepulse interval 

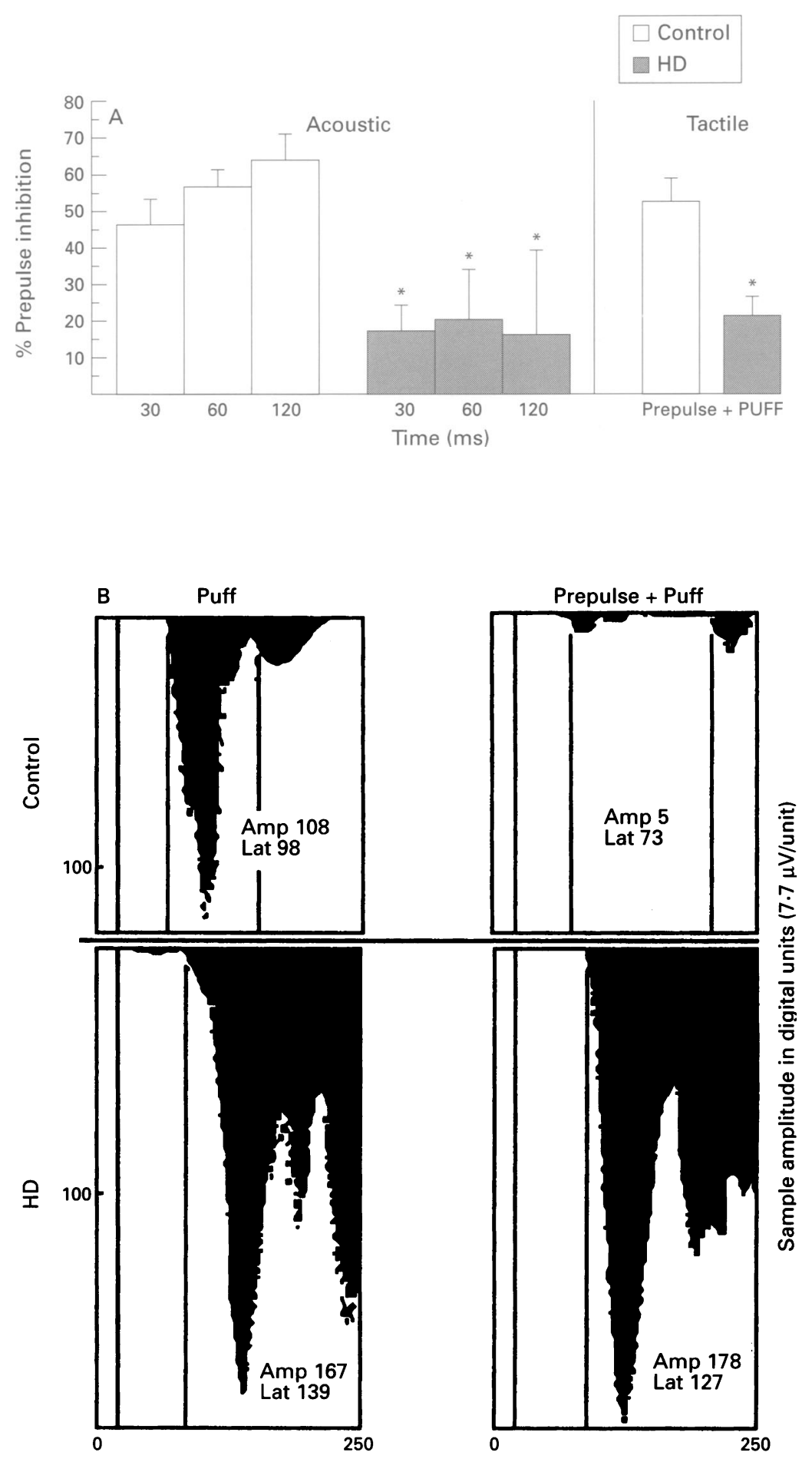

Time after stimulus onset (ms)

Figure 1 (A) Prepulse inhibition of acoustic and tactile startle reflex in patients with Huntington's disease (HD; $n=11)$ and normal controls $(n=11)$ in session 1 . * Significant effect of diagnosis, $p<0.05$. (B) EMG waveforms from a control subject and a patient with Huntington's disease, recorded from the orbicularis oculi. Responses in both are from identical trials ("PUFF" or "prepulse + PUFF", trials No 104 and 103 from session 1 respectively). Near complete startle gating is evident in the waveform recorded from the control subject, whereas an absence of startle gating is evident in the waveform recorded from the patient with Huntington's disease. Also evident is the increased reflex latency in the patient with Huntington's disease compared with the control subject, as well as the presence of latency facilitation (reduced latency on "prepulse + PUFF" trial compared to "PUFF" alone trial) in both control subjects and patients with Huntington's disease. Finally, the waveforms from both controls and patients with Huntington's disease exhibit several late components that follow the initial reflex peak $\left(R_{t}\right)$. This $R_{1}$ component is the element of the startle waveform that is traditionally used in the calculation of PPI. ${ }^{1821232728} 47-50$ Additional studies of the more complex later waveform components in patients with Huntington's disease may provide valuable information. over the $120 \mathrm{~ms}$ range. Thus there is more PPI on $120 \mathrm{~ms}$ trials compared with $30 \mathrm{~ms}$ trials in controls (paired $t$ test: $t=3 \cdot 30$, df 8 , $\mathrm{p}<0.015$ ), but not in patients with Huntington's disease $(t<1)$. Analysis of tactile PPI also showed less PPI in patients with Huntington's disease $(F=8.63$, df $1,19, \mathrm{p}<$ $0.01)$. Figure 1B shows examples of EMG waveforms from a control subject and a patient with Huntington's disease.

Peak startle latency was increased in patients with Huntington's disease compared with controls for both acoustic and tactile trials, but the modulatory effects of prepulses on reflex latency (latency facilitation) remained intact in patients with Huntington's disease (figs 1B and 2). For acoustic trials, analysis of peak startle latency showed an effect of group $(F=6.25$, df $1,14, \mathrm{p}<0.03)$, and an effect of trial type $(F=5.65$, df $3,42, \mathrm{p}<0.003)$, but no group $\times$ trial type interaction $(F=2 \cdot 34$, df 3,42 , NS). Similarly, for tactile trials, ANOVA showed effects of group $(F=20 \cdot 89$, df $1,14, \mathrm{p}<0.0005)$ and trial type $(F=5.84$, df $1,14, p<0.03$ ), but no group $\times$ trial type interaction $(F<1)$. Thus the startle reflex was slowed in patients with Huntington's disease in both acoustic and tactile modalities. Most importantly, however, patients with Huntington's disease retained the modulatory effects of the prepulse on reflex latency, despite the significant loss of the modulatory effects of the prepulse on startle amplitude. Clearly, the prepulse modified startle characteristics (latency) in patients with Huntington's disease, but did not gate the startle response.

It is possible that the increased startle latency and reduced PPI in patients with Huntington's disease reflected the non-significantly older age in patients with Huntington's disease (mean age 52.00 (SEM 4.04) compared with controls (mean age 49.36 (3.12); $F<1$ ). Spearman rank correlations were used to test this hypothesis and showed no significant correlation between age and PPI in control subjects $\left(R_{s}=0.03,0.08,-0.18\right.$ and -0.20 for $30 \mathrm{~ms}, 60 \mathrm{~ms}, 120 \mathrm{~ms}$, and tactile trials respectively), consistent with our findings in larger samples of normal controls. ${ }^{20}$ More robust negative correlations between age and PPI were noted in patients with Huntington's disease $\left(R_{s}=0.33,-0.78\right.$, -0.55 , and -0.64 for $30 \mathrm{~ms}, 60 \mathrm{~ms}, 120 \mathrm{~ms}$, and tactile trials respectively; $p<0.05$ for 60 $\mathrm{ms}$ and tactile comparisons). These negative correlations in patients with Huntington's disease suggest that increased age is associated with reduced PPI. Positive correlations between age and peak startle latency were noted in patients with Huntington's disease $\left(R_{\mathrm{s}}=0.64,0.79,0.64,0.29,0.64\right.$ and 0.76 for P-ALONE, $30 \mathrm{~ms}, 60 \mathrm{~ms}, 120 \mathrm{~ms}$, PUFF and prepulse + PUFF trials respectively; $p<$ 0.05 for $30 \mathrm{~ms}$ and prepulse + PUFF trials), whereas no significant positive correlations between age and peak startle latency were noted in controls $\left(R_{\mathrm{s}}<0.20\right.$, all comparisons). The positive correlations between age and peak startle latency in patients with 
Figure 2 Peak startle latency in patients with Huntington's disease (HD; $n=11)$ and normal controls $(n=11)$ for acoustic startle (top) and tactile startle (bottom) in session 1. * Significant effect of diagnosis, $p<0.05$.
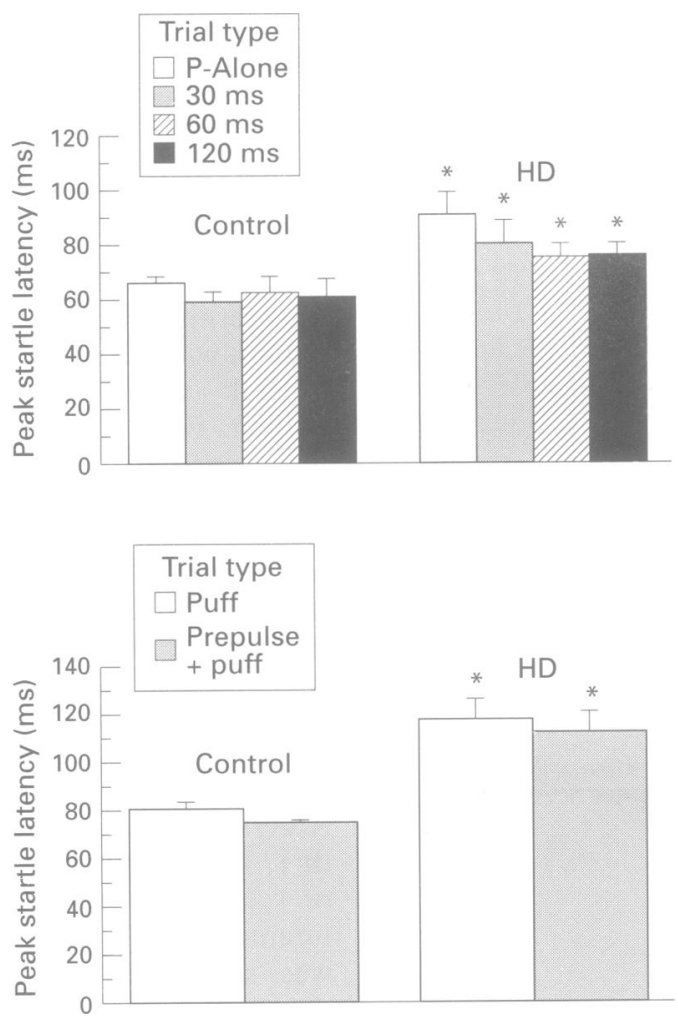

Huntington's disease suggest that increased age is associated with slowing of the startle reflex in these subjects. Age and startle amplitude did not correlate significantly in controls or patients with Huntington's disease $(-0.16$ $<\mathrm{R}_{\mathrm{s}}<0.20$, all comparisons). Thus whereas increased age alone cannot account for the significant loss in PPI and increased startle latency in patients with Huntington's disease some combination of advanced age and a diagnosis of Huntington's disease may be related to the abnormalities in startle response. Although these findings must be interpreted with caution due to small sample size, one explanation for these correlations is that the PPI loss and reflex slowing varies with the progression of CNS pathology in patients with Huntington's disease.

Results in session 2 were similar to those in session 1. Startle amplitude on P-ALONE trials did not differ between groups (mean amplitudes (SEM): control $=61.36(8 \cdot 15)$; Huntington's disease $=57.32(13.30) ; F<$ 1). Startle habituation was evident in controls and patients with Huntington's disease: there was an effect of trial block $(F=22 \cdot 08$, df $1,20, \mathrm{p}<0.0001)$, and no block $\times$ diagnosis interaction $(F<1)$. As in session 1 , patients with Huntington's disease exhibited normal acoustic startle amplitude; also, the division of session 2 into two equal blocks showed that patients with Huntington's disease exhibit normal startle habituation.

The PPI in patients with Huntington's disease was also impaired in session 2 (fig 3). An ANOVA showed effects of diagnosis $(F=17 \cdot 84$, df $1,20, \mathrm{p}<0.0005)$ and trial type $(F=5.80$, df $3,60, \mathrm{p}<0.002)$, and a diagnosis $\times$ trial type interaction $(F=4.37$, df $3,60, \quad p<0.008)$. Patients with Huntington's disease showed significantly less
PPI than controls for 4,8 , and $16 \mathrm{~dB}$ trials $(F$ $=6.92,13.83$, and 17.78 respectively). Control subjects showed the normal modulatory pattern of PPI, in this case with more inhibition elicited by more intense prepulses, whereas patients with Huntington's disease failed to show this modulatory effect of increasing prepulse intensity. The PPI in patients with Huntington's disease in session 2 averaged negative values: startle amplitude on prepulse trials was actually increased compared with amplitude on P-ALONE trials in this Huntington's disease group. Prepulse potentiation has been reported in humans using $2000 \mathrm{~ms}$ prepulse intervals, ${ }^{21}$ and in rats treated with the D2 dopamine agonist quinpirole. ${ }^{22}$ Whereas several individual patients with Huntington's disease in session 1 exhibited prepulse potentiation, the average positive PPI values in the session 1 Huntington's disease group may reflect differences from session 2 either in the trial parameters, session design, patient characteristics, or EMG recording systems.

Figure 4 shows the startle latency in session 2 . As in session 1, peak latency was significantly increased in patients with Huntington's disease compared with controls, and again, the modulatory effects of prepulses on reflex

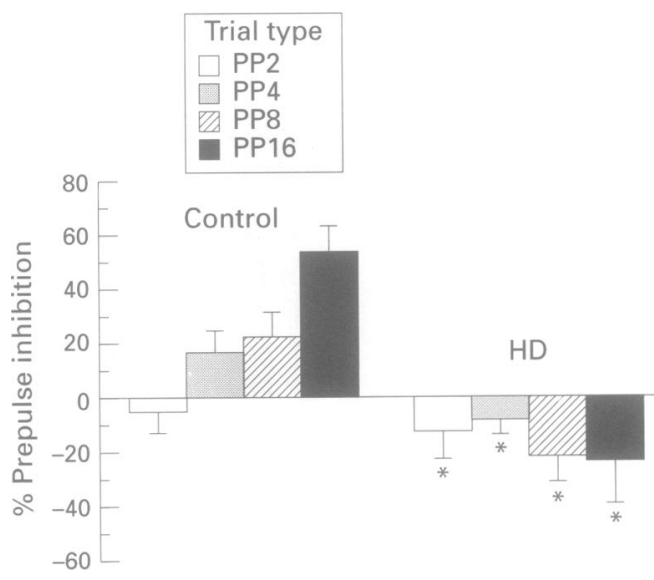

Figure 3 Prepulse inhibition of acoustic startle in patients with Huntington's disease (HD; $n=11$ ) and normal controls $(n=11)$ in session 2 . ${ }^{\star}$ Significant effect of diagnosis, $p<0.05$.

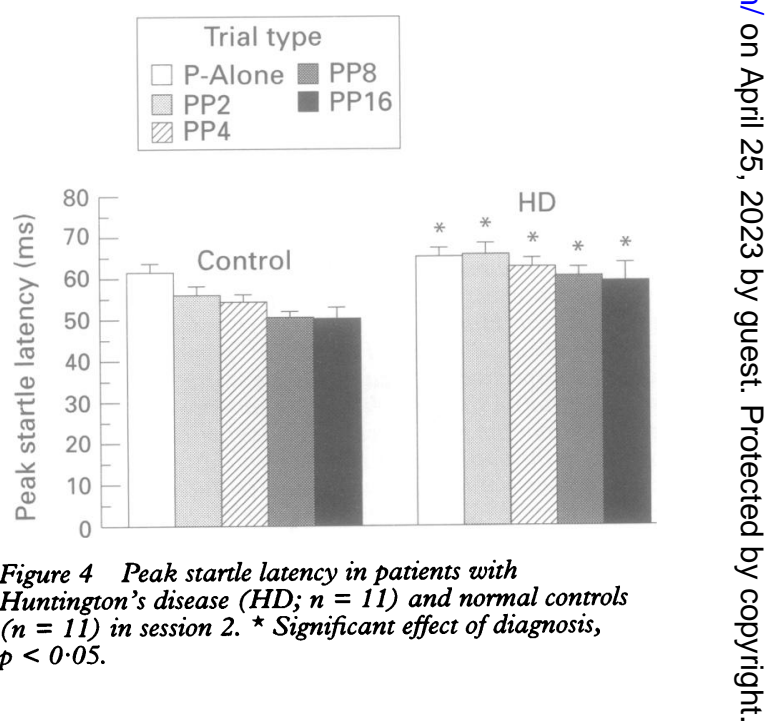


latency (latency facilitation) remained intact in patients with Huntington's disease. An ANOVA showed an effect of group ( $F=$ 11.85 , df $1,20, p<0.003)$, an effect of trial type $(F=14 \cdot 63$, df $4,80, \mathrm{p}=0 \cdot 0001)$, but no group $\times$ trial type interaction $(F<1)$.

In session 2 , unlike session 1 , age differed significantly between patients with Huntington's disease (mean age 48.09 (SEM 4.39 )) and controls (mean age 30.73 (SEM $2.51) ; F=11.79$, df $1,20, \mathrm{p}<0.003)$. For this reason, a separate analysis compared PPI in the six oldest controls $(\mathrm{M}: \mathrm{F}=3: 3$; mean age 35.67 (SEM 3.19)) and the six youngest patients with Huntington's disease ( $\mathrm{M}: \mathrm{F}=$ $5: 1$; mean age $38.67(1.63))$ tested in session 2 (age comparison control $v$ Huntington's disease, $F<1$ ). The PPI in these patients with Huntington's disease was also significantly less than PPI in the oldest controls. An ANOVA showed an effect of group ( $F=$ 16.277 , df $1,10, p<0.003$ ), an effect of trial type $(F=5.02$, df $3,30, \mathrm{p}<0.007)$, and no group $\times$ trial type interaction $(F<1)$. As PPI is greater in male than female controls, ${ }^{23}$ the over-representation of women among the age matched controls should bias against the PPI deficit found in patients with Huntington's disease. With the small sample size and relatively uniform absence of PPI, no significant correlations were noted between PPI and age ( $p>0.05$, all comparisons), age at first diagnosis ( $p>0.05$ all comparisons), or interval between first diagnosis and testing ( $p>0.05$, all comparisons) (for example, $R_{s}$ for PPI on $16 \mathrm{~dB}$ trials-most comparable with $60 \mathrm{~ms}$ trials in session 1-and age, age at diagnosis, and interval between diagnosis and testing were $-0.46,-0.47$, and -0.18 respectively).

We assessed the relation between cognitive impairment-as reflected by dementia rating scale scores-and startle abnormalities in patients with Huntington's disease by simple regression analyses. There was no significant correlation between dementia rating scale scores and PPI for any prepulse condition in session 1 or session $2(0.38>r>-0.58 ; \mathrm{p}>$ 0.05 all comparisons). As nearly identical PALONE stimuli were used in session 1 and session 2, P-ALONE latencies were pooled from these two sessions. A simple regression analysis showed a significant correlation between startle latency and dementia rating scale scores, with longer reflex latencies associated with lower dementia rating scale scores $(r$ $=-0.77, \mathrm{p}<0.0005)$. Similar correlations were noted when latencies from session 1 and session 2 were analysed separately (session 1 : $r=-0.71$; session 2: $r=-0.71$ ). As age was significantly correlated with reflex latency in session 1, it is important that there was no significant relation between age and dementia rating scale score $(r=-0 \cdot 24, \mathrm{NS})$.

Shoulon and Fahn ratings of total functional capacity $(13=$ normal, $0=$ require total care $)^{24}$ were available on 10 subjects at the time of testing for session 2. Correlations between total functional capacity and PPI were positive, but not statistically significant, for all prepulse conditions $(0.50>r>0.19$; $\mathrm{p}>0.05$ all comparisons). It is interesting that the only two patients with Huntington's disease who exhibited consistent PPI (mean PPI across all conditions $=32 \cdot 7 \%$ ) had the highest total functional capacity scores (10 and 12); the remaining eight exhibited no overall prepulse inhibition (mean PPI across all conditions $=-25 \cdot 7$ ) and had low total functional capacity scores (mean $=5 \cdot 38$ ). Chorea ratings, ${ }^{25}$ available for 10 patients, did not correlate significantly with mean PPI ( $r=$ $-0 \cdot 12)$. Results from the Stroop test (table) showed expected deficits in all three Stroop conditions in patients with Huntington's disease. ${ }^{26}$ Compared with controls, patients with Huntington's disease recorded lower scores in the word task $(F=43.54$, df $1,16, \mathrm{p}<$ $0.0001)$, the colour task $(F=180.42$, df 1,16 , $\mathrm{p}<0.0001)$, and the interference task $(F=$ 86.55 , df $1,16, \mathrm{p}<0.0001)$. The relative interference score, calculated as the word score divided by the interference score, was significantly greater in patients with Huntington's disease than in controls ( $F=$ 4.52 , df $1,16, p<0.05)$. This suggests that compared with controls, patients with Huntington's disease had more difficulty in the interference condition relative to their own "baseline" word scores.

Correlations of Stroop test scores, dementia rating scale scores, and startle latencies showed that slowing of the startle reflex in patients with Huntington's disease was significantly correlated with performance in the word task $(r=-0.76, \mathrm{p}<0.05)$, and with the relative interference score $(r=-0.80, \mathrm{p}<$ 0.02 ), but not with performance in the colour or interference tasks $(R=-0.26$ and -0.05 , respectively; $\mathrm{p}>0.05$, both comparisons). By contrast, Stroop test scores in control subjects did not correlate significantly with any startle measure, as we have reported previously $(0.16>r>-0.55 ; \mathrm{p}>0.05$ all comparisons)..$^{20}$ Other studies have shown strong correlations between Stroop deficits, overall cognitive impairment, and caudate atrophy in patients with Huntington's disease. ${ }^{24}$ In our small sample, dementia rating scale scores in patients with Huntington's disease were significantly correlated with performance in the word, colour, and interference tasks $(r=$ $0.95,0.72$, and $0.71 ; \mathrm{p}<0.0005,0.05$, and 0.05 respectively) but were not significantly correlated with the relative interference score $(r=0 \cdot 16, \mathrm{NS})$.

Mean Stroop test score (SEM)

\begin{tabular}{lrr}
\hline Condition & Control $(n=10)$ & $\begin{array}{l}\text { Huntington's } \\
\text { disease }(n=8)\end{array}$ \\
\hline Word & $108 \cdot 40(7 \cdot 21)$ & $46 \cdot 00(5 \cdot 46)^{\star}$ \\
Colour & $78 \cdot 40(2 \cdot 46)$ & $26 \cdot 25(3.08)^{\star}$ \\
Interference & $49 \cdot 00(2 \cdot 74)$ & $15 \cdot 13(2 \cdot 18)^{\star}$ \\
Relative interference & $2 \cdot 28(0 \cdot 19)$ & $3 \cdot 28(0 \cdot 47)^{\star}$ \\
\hline${ }^{\star}$ p $<0.05 v$ control group. & \\
tWord score/interference score.
\end{tabular}




\section{Discussion}

The degree to which a weak sensory "prepulse" inhibits or "gates" a potent motor reflex is an operational measure of sensorimotor gating. We report that patients with Huntington's disease are impaired in their ability to inhibit normally a reflex response to an intense auditory or tactile stimulus. There are several possible explanations that might account for these abnormalities in sensorimotor gating.

Firstly, it could be argued that the loss of PPI in patients with Huntington's disease reflects factors not directly related to the pathophysiology of Huntington's disease, such as generalised weakness or a reduced ability to detect an auditory prepulse. The loss of PPI in these patients cannot be easily attributed to generalised debilitation or weakness, as startle amplitude-a measure of motor reactivity -is not reduced. This suggests that the "primary" pontine reticular startle circuit is intact in patients with Huntington's disease, and is consistent with our previous findings from preclinical, ${ }^{9-11} 131522$ and clinical studies ${ }^{1820212327}$ that startle amplitude and PPI are controlled by separate neural mechanisms. A failure to "detect" the prepulse cannot account for reduced PPI in patients with Huntington's disease, as the patients were screened for hearing deficits, and because prepulse facilitation was intact in these same patients. Thus there is quantitative evidence of the modulatory influence of prepulses on the startle reflex in these patients, despite the loss or absence of PPI.

Secondly, it is possible that cognitive impairment in patients with Huntington's disease might be accompanied by attentional deficits that weaken the inhibitory effects of prepulses on the startle reflex. Such an explanation is incompatible with the interpretation that PPI reflects largely "preattentive" processes, ${ }^{28}$ and that a prepulse interval of 30 ms-which produces robust PPI in controls but not patients with Huntington's diseaseis too short to evoke attentional mechanisms. In fact, PPI in patients with Huntington's disease was not correlated significantly with cognitive impairment as measured by dementia rating scale scores. It is possible that a loss of PPI, or perhaps the increase in reflex latency, reflects drug induced changes in startle gating caused by the use of dopamine antagonists in patients with Huntington's disease. Such an interpretation is not compatible with findings that neuroleptic drugs increase PPI in rats ${ }^{15}$ and humans with schizophrenia, ${ }^{16}$ and that startle latency is not increased in schizophrenic patients treated with much higher doses of antipsychotic drugs than were the patients in the present study. ${ }^{18}$

Thirdly, it could be argued that the loss of PPI in patients with Huntington's disease reflects the slightly increased age in these patients, compared with controls. This interpretation is not supported by the finding of lower PPI in patients with Huntington's disease than in similar age controls in session 2 . The possibility that age alone accounts for the reflex abnormalities in patients with Huntington's disease is refuted by the finding that PPI and startle latency do not significantly correlate with age in normal controls in the present study and in previous studies with larger samples. ${ }^{20}$ The stronger correlation of age with gating failure and increased reflex latency in patients with Huntington's disease suggests that these abnormalities are linked to the disease progression in Huntington's disease. This interpretation must be made with caution given the small samples in the present study.

Previous studies have reported abnormalities in the blink reflex in patients with Huntington's disease. Increased latency and reduced habituation of electrically evoked blinks were noted in patients with Huntington's disease compared with normal controls and unaffected family members. ${ }^{28}$ This is consistent with our present findings of increased latency in both acoustic and tactile startle responses in patients with Huntington's disease. Reflex slowing in such patients was correlated significantly with the degree of cognitive impairment measured by the dementia rating scale, and was also correlated significantly with the performance disruptive effects of interference on the Stroop test. The failure to detect habituation deficits in our study might reflect the fact that the paradigm used is not designed to be optimally sensitive to changes in habituation, which are best detected by multiple presentations of a single stimulus type. Others, however, have reported normal or even enhanced habituation of electrically stimulated blinks in patients with Huntington's disease. ${ }^{29} 30$

We have no direct evidence that the loss of PPI in our patients reflects degenerative changes within the striatum. Such evidence would include significant correlations between PPI and neuroimaging detected volume changes or metabolic changes in the striatum in these patients. This experimental approach has been initiated in studies of PPI in patients with schizophrenia, in whom there is a significant negative correlation $(R=$ $-0.77)$ between PPI and lenticular nucleus volume assessed by MRI. ${ }^{31}$ As patients with Huntington's disease also exhibit atrophy ${ }^{32}$ and hypometabolism ${ }^{33}$ in cortical areas, it is possible that reduced PPI might reflect cortical dysfunction rather than striatal degeneration. Such a mechanism is not supported by animal studies, in which PPI in adult rats is not significantly reduced by large lesions of the medial prefrontal cortex, ${ }^{34}$ the frontal poles, ${ }^{35}$ the entire frontal cortex,,$^{36}$ the dorsal hippocampus and overlying parietal cortex, ${ }^{36}$ the parietal cortex alone, ${ }^{36}$ or the ventral hippocampus. ${ }^{34} 37$

Although the cause of striatal degeneration in Huntington's disease is not well understood, several investigators have hypothesised that loss of striatal medium spiny cells results from an endogenous excitotoxin, similar to kainic or quinolinic acid. Quinolinic acid is a product of the kynurenine pathway. Increased activity of a quinolinic acid synthetic enzyme 
has been reported in postmortem brain tissue from patients with Huntington's disease. ${ }^{38} 39$ In rats, infusion of quinolinic acid results in a selective destruction of neurons, leaving fibres of passage intact. ${ }^{4041}$ Recently, we found that PPI is impaired in rats after quinolinic acid lesions of the anteroventral ${ }^{12}$ or dorsal/posterior striatum (Kodsi and Swerdlow, unpublished data) and after picrotoxin infusion into corresponding regions of the anteroventral ${ }^{913}$ or dorsal/posterior globus pallidus (Kodsi and Swerdlow, unpublished data). Impaired startle gating in patients with Huntington's disease can thus be mimicked in rats by striatal damage caused by a neurotoxin that has been implicated in the pathophysiology of Huntington's disease, or by pharmacological interruption of striatopallidal GABAergic neurotransmission.

Deficits in PPI have been reported in patients with schizophrenia ${ }^{18}$ and in patients with obsessive compulsive disorder ${ }^{27}$; similar findings have been reported in patients with Tourette's syndrome. ${ }^{42} 43$ Importantly, the pattern of PPI deficits varies between different gating disorders. For example, whereas the total amount of PPI is reduced in these patients with Huntington's disease compared with matched controls, PPI in patients with obsessive compulsive disorder and schizophrenia exhibits "normal" patterns of stimulus modulation: PPI increases with increasing prepulse intensity, with maximal inhibition seen at short $(30-60 \mathrm{~ms})$ prepulse intervals. ${ }^{51}$ By contrast, the modulatory influences of prepulse parameters on PPI are totally abolished in Huntington's disease. This suggests that the loss of PPI in patients with Huntington's disease reflects a complete "disconnection" of the primary startle circuit from forebrain elements that modulate the inhibitory effects of the prepulse. By contrast, PPI deficits in patients with schizophrenia or obsessive compulsive disorder seem to reflect a reduced sensitivity to the inhibitory effects of the prepulse, or a diminished influence of inhibitory forebrain circuitry on the primary startle circuit. As our preclinical studies suggest that the modulatory effects of prepulse intensity and interval on PPI are controlled at discrete sites within the startle gating circuitry, ${ }^{12}$ it might ultimately be possible to link different patterns of PPI deficits to separate substrates within limbic motor gating circuitry.

Genetic studies have associated a gene on the G8 fragment of chromosome 4 with the autosomal dominant transmission of Huntington's disease.$^{44}$ More specific characterisation of the Huntington's disease gene and its relation to the pathophysiology of the disease will benefit from the identification of objective phenotypic markers of impaired striatal function and gating. The PPI may serve as such a marker, because it is an objective and highly quantitative measure of sensorimotor gating with a discrete underlying neural basis, that is impaired in Huntington's disease. Startle reflex latency is also an objective, quantifiable variable that seems to corre- late significantly with cognitive impairment and the performance disruptive effects of interference in Huntington's disease. As startle measures are non-invasive, brief (a typical session lasting 25 minutes), and can be obtained with portable testing units, it would be realistic to pursue larger studies of sensorimotor gating and startle reflex latency in families of Huntington's disease probands. A similar strategy is being used with the event related potential $\mathrm{P} 50$ gating paradigm in a large proband of schizophrenic patients. ${ }^{45}$

In summary, sensorimotor gating is impaired in patients with Huntington's disease compared with controls. The loss of sensorimotor gating is evident in both acoustic and tactile modalities, but is accompanied by normal startle amplitude, normal habituation, and normal prepulse latency facilitation. The pattern of impaired gating in Huntington's disease is distinct from the pattern of deficits previously reported in patients with schizophrenia or obsessive compulsive disorder, and suggests a complete or near complete disconnection of forebrain modulatory influences on "primary" startle circuitry in the reticular formation in Huntington's disease.

We gratefully acknowledge the outstanding assistance of Ms Joyce Sprock, Ms Heidi Hartston, and Ms Pamela Auerbach, and the staff of the UCSD Genetically Handicapped Person's Program, including Shirley Fenner, RN and Ms Shannon Johnson. Studies were supported by NIMH FIRST award MH 48381 (NRS) and NIMH grant MH42228 (DLB, MAG, NRS). Some findings have been summarised previously, ${ }^{\text {th }}$ and data from some of the control subjects have been included in a separate report of reflex patterns in a normal population. Preliminary results of these studies were presented population. of the International Congress on Schizophrenia Research of the International Congress on Schizophrenia Research, Tucson, Arizona, 1990, and the American College
Neuropsychopharmacology, San Juan, Puerto Rico, 1990.

1 Groves PM. A theory of the functional organization of the neostriatum and the neostriatal control of voluntary movement. Brain Res Rev 1983;5:109-32.

2 Penney JB, Young AB. Speculations on the functional anatomy of basal ganglia disorders. Ann Rev Neurosci 1983;6:73-94.

3 Bruyn GW. Huntington's chorea: historical, clinical and laboratory synopsis, In: Vinken P, Bruyn GW, eds. Handbook of clinical neurology. Vol 6. Amsterdam: North Holland 1968:298-378.

4 Reynolds GP, Pearson SJ. Brain GABA levels in asymptomatic Huntington's disease. $N$ Engl $\mathcal{f}$ Med 1990;323: matic
692 .

5 Ison JR, McAdam DW, Hammond GR. Latency and amplitude changes in the acoustic startle reflex produced by variations in auditory prestimulation. Physiol Behav by variations in

6 Davis M, Gendelman D, Tischler M, Gendelman P. A primary acoustic startle circuit: lesion and stimulation studies. F Neurosci 1982;2:791-805.

7 Caine SB, Geyer MA, Swerdlow NR. Hippocampal modulation of acoustic startle and prepulse inhibition in rats. Pharmacol Biochem Behav 1992;43:1201-8.

8 Caine SB, Geyer MA, Swerdlow NR. Carbachol infusion into the dentate gyrus disrupts sensorimotor gating of startle in rats. Psychopharmacology (Berl) 1991;105: 347-54.

9 Swerdlow NR, Braff DL, Geyer MA. GABAergic projection from nucleus accumbens to ventral pallidum mediates dopamine-induced sensorimotor gating deficit of acoustic startle in rats. Brain Res 1990;532:146-50.

Swerdlow NR, Braff DL, Masten VL, Geyer MA. Schizophrenic-like sensorimotor gating abnormalities in rats following dopamine infusion into the nucleus accum-
bens. Psychopharmacology (Berl) 1990;101:414-20.

11 Swerdlow NR, Caine SB, Braff DL, Geyer MA. Neural substrates of sensorimotor gating of the startle reflex: a review of recent findings and their implications. fournal of Psychopharmacology 1992;6:176-90.

12 Swerdlow NR, Wan F, Kodsi M, Hartston H, Caine S Limbic cortico-striato-pallido-pontine substrates of startle gating. Biol Psychiatry 1993;33:62A.

13 Swerdlow NR, Geyer MA. Prepulse inhibition of acoustic startle in rats after lesions of the pedunculopontine nucleus. Behav Neurosci 1993;107:104-17.

14 Madis S. Mental status examination for organic mental syndrome in the elderly patient. In: Bellack L, Karasu 
TB, eds. Geriatric psychiatry. New York: Grune and Stratton, 1976:77-121

15 Swerdlow NR, Geyer MA. Clozapine and haloperidol in an animal model of sensorimotor gating deficits in schizophrenia. Pharmacol Biochem Behav 1993;44: $741-4$.

16 Wu JC, Potkin SG, Ploszaj DI, Lau V, Telford J, Richmond G. Clozapine improves sensory gating more than haldol. American Psychiatric Association more than haldol. American Psychic

17 Butler RW, Jenkins MA, Braff DL. On the abnormality of normal comparison groups: The identification of psychosis-proneness and substance abuse in putative normal research subjects. Am f Psychiatry 1993;150 1386-91.

18 Braff DL, Grillon C, Geyer MA. Gating and habituation of the startle reflex in schizophrenic patients. Arch Gen Psychiatry 1992;49:206-15.

19 Stroop JR. Studies of interference in serial verbal reactions. f Exp Psychol 1935;18:643-62.

20 Swerdlow NR, Filion D, Geyer MA, Braff DL. "Normal" personality correlates of sensorimotor, cognitive and visuo-spatial gating. Biol Psychiatry 1994 (in press).

21 Braff D, Stone C, Callaway E, Geyer M, Glick I, Bali L Prestimulus effects on human startle reflex in normals Prestimulus effects on human startle reflex in norma

22 Wan FJ, Swerdlow NR. Intra-accumbens infusion of quinpirole impairs sensorimotor gating of acoustic startle in

23 Swerdlow NR, Monroe SM, Hartston HJ, Braff DL, Geyer MA, Auerbach PP. Men are more inhibited than women by weak prepulses. Biol Psychiatry 1993;34: 253-60.

24 Shoulson I, Fahn S. Huntington disease: clinical care and evaluation. Neurology 1979;29:1-3.

25 Folstein SE, Jensen B, Leigh RJ, Folstein MF. The measurement of abnormal movement: methods developed for Huntington's disease. Neurobehavioral Toxicology and Teratology 1983;5:605-9.

26 Butters N, Sax D, Montgomery K, Tarlow S. Comparison of the neuropsychological deficits associated with early and advanced Huntington's disease. Arch Neurol and advanced

27 Swerdlow NR, Benbow CH, Zisook S, Geyer MA, Braff DL. A preliminary assessment of sensorimotor gating in patients with obsessive compulsive disorder (OCD). Biol Psychiatry 1993;33:298-301.

28 Braff DL, Geyer MA. Sensorimotor gating and schizophrenia: human and animal model studies. Arch Gen Psychiatry 1990;47:181-8.

29 Esteban A, Mateo D, Gimenez-Roldan S. Early detection of Huntington's disease. Blink reflex and levodopa load in presymptomatic and incipient subjects. $f$ Neurol Neurosurg Psychiatry 1981;44:43-8.

30 Ferguson IT, Lenman JAR, Johnston BB. Habituation of orbicularis oculi reflex in dementia and dyskinetic states. or Neurol Neurosurg Psychiatry 1978;41:824-8.

31 Braff DL, Geyer MA, Swerdlow NR, Jernigan T. Gating deficits, neural circuits, and schizophrenia. Biol Psychiatry 1993;33:88A.

32 McCaughey WTE. The pathologic spectrum of Huntington's chorea. F Nerv Ment Dis 1961;133:91-103.

33 Kuwert T, Lange H, Langen K, Herzog H, Aulich A, Feinendegen LE. Cortical and subcortical glucose consumption measured by PET in patients with
Huntington's disease. Brain 1990;113:1405-23.

34 Swerdlow NR, Lipska B, Weinberger D, Braff DL, Jaskiw $\mathrm{G}$, Geyer MA. Effects of frontal cortex and hippocampa lesions on apomorphine-disrupted startle gating. Bio Psychiatry 1994;35:707.

35 Hammond GR. Frontal cortex lesions and prestimulus inhibition of the rat's acoustic startle reaction. Physio Psychol 1974;2:151-6.

36 Groves PM, Boyle RD, Welker RL, Miller SW. On the mechanism of prepulse inhibition. Physiol Behav $1974 ; 12: 367-75$

37 Kemble ED, Ison JR. Limbic lesions and the inhibition of startle reactions in the rat by conditions of preliminary stimulation. Physiol Behav 1971;7:925-8.

38 Schwarcz R, Shoulson I. Excitotoxins and Huntington's disease. In: Coyle JT, ed. Animal models of dementia. New York: AR Liss, 1987:39-68.

39 Schwarcz R, Tamminga CA, Kurlan R, Shoulson I. Cerebrospinal fluid levels of quinolinic acid in Cerebrospinal fluid levels of quinolinic acid in
Huntington's disease and schizophrenia. Ann Neurol

40 Beal MF, Brouillet E, Jenkins B, Srivastava R, Roy D, Rosen B, Hyman B. Local and systemic administration of 3-nitropropionic acid results in excitotoxic striatal lesions. Abstr Soc Neurosci 1992;18:84.

41 Schwarcz R, Whetsell WO, Mangano RM. Quinolinic acid: an endogenous metabolite that produces axonsparing lesions in the rat striatum. Science 1983; 219:316-8.

42 Smith SJS, Lees AJ. Abnormalities of the blink reflex in Gilles de la Tourette syndrome. 7 Neurol Neurosurg Psychiatry 1989;52:895-80.

43 Castellanos FX, Fine EJ, Kaysen DL, Kozuch PL Hamburger SD, Rapoport JL. Sensorimotor gating in boys with Tourette's syndrome and attention deficit hyperactivity disorder. Abstracts of the Society for Neuroscience 1993;19:991.

44 Huntington's Disease Collaborative Group. A novel gene containing a trinucleotide repeat that is expanded and unstable on Huntington's disease chromosomes. Cell 1993;72:971-83.

45 Coon H, Plaetke R, Holik J, Hoff M, Myles-Worsley M, Waldo $M$, et al. Use of a neurophysiological trait in link1993;34:277-89. of schizophrenia. Biol Psychiatry

46 Swerdlow NR, Caine SB, Geyer MA, Swenson MR, Downs NS, Braff DL. Sensorimotor gating deficits in schizophrenia and Huntington's disease and in rats after manipulation of hippocampus-accumbens circuitry. Abstracts of the International Congress of Schizophrenia Research, Tucson, Arizona, 1990

47 Graham F. The more or less startling effects of weak prestimulation. Psychophysiol 1975;12:238-48.

48 Hackley SA, Graham FK. Effects of attending selectively to the spatial position of reflex-eliciting and reflexmodulating stimuli. $\mathcal{F}$ Exp Psychol Hum Percept Perform $1987 ; 13: 411$.

49 Blumenthal TD, Gescheider GA. Modification of the acoustic startle reflex by a tactile prepulse: the effects of stimuius onset asynchrony and prepulse intensity. Psychophysiology 1987;24:320-7.

50 Blumenthal TD, Levey BJ. Prepulse rise time and startle reflex modification: different effects for discrete andcontinuous prepulses. Psychophysiology 1989;26:

\section{NEUROLOGY IN LITERATURE}

\section{Some speech disorders}

Continued from page 191.

Marcel Proust, 1913, Remembrance of things past. Vol 1 Swann's way

Moreover, the name Swann, with which I had for so long been familiar, had now become for me (as happens with certain aphasiacs in the case of the most ordinary words) a new name.

Fames Foyce, 1922, Ulysses

Your attention! We're nae that fou. The Leith Police dismisseth us.

Sinclair Lewis, 1923, Babbitt

"And there's no if, and or but about it!"

Marcel Proust, 1927, Time regained, Vol 3

Of the two, one, the intellectual one, passed his time in complaining that he suffered from progressive aphasia, that he constantly pronounced one word, one letter by mistake for another.

PG Wodehouse, undated, The story of Webster; from Mr Mulliner's relations

Webster, like the Stag at Eve, had now drunk his fill. He had left the pool of alcohol and was walking round in slow, meditative circles. From time to time he mewed tentatively, as if he were trying to say "British Constitution." His failure to articulate the syllables appeared to tickle him. ...

Regional Geurscion PERKIN Charing Cross Centre, London W6 8RF, UK

1 Dax M Lésions de la moitié gauche de l'encéphale coincidant avec l'oubli des signes de la pensée (Lu à Montpellier en 1836) Gazette hebdomadaire des sciences médicales de bordeaux 1865;2:259-60.

2 Monrad-Krohn GH. The clinical examination of the nervous system. 8th ed, London: HK Lewis, 1947. 